\title{
Seasonal changes of rumen and intestine morphology of the Qinghai yak (Bos grunniens)
}

\author{
Bao A. Ding ${ }^{1}$, Shuang Q. Ma ${ }^{1}$, Zong R. $\mathrm{Li}^{1}$, Xi L. $\mathrm{Li}^{1}$ and Stephen R. Madigosky ${ }^{2}$
}

1. State Key Laboratory of Plateau Ecology and Agriculture, College of Agriculture and Animal Husbandry, Qinghai University, Xining 810016, China; 2. Department of Environmental Science and Biology, One University Place, Chester, PA, 19013, Widener University. USA.

Corresponding author: Zong R. Li, e-mail:lizongrenqd@126.com

Co-authors: BAD: dingbaoan1967@aliyun.com, SQM: 407191323@qq.com, XLL: 786621475@qq.com, SRM: smadigosky@hotmail.com

Received: 22-03-2018, Accepted: 06-07-2018, Published online: 16-08-2018

doi: 10.14202/vetworld.2018.1135-1138 How to cite this article: Ding BA, Ma SQ, Li ZR, Li XL, Madigosky SR (2018) Seasonal changes of rumen and intestine morphology of the Qinghai yak (Bos grunniens), Veterinary World, 11(8): 1135-1138.

\begin{abstract}
Aim: The aim of the current study was to investigate the effects of seasonal changes in grass quality on the ruminal and intestinal morphology of male Qinghai yaks.

Materials and Methods: A total of four male yaks with the same age of 4 years old from each season (summer and winter) were randomly selected and slaughtered to determine the effect of different season on intestinal morphology of yak in the Qinghai-Tibetan Plateau.

Results: The histological analysis shows that male yak has the longer and wider papillae in rumen in green season. The height of villi in duodenum and jejunum was significantly higher in green season, and the width of villi on duodenum, jejunum, ileum, and rectum was significantly wider in green season. Surface area of villi and crypt depth in duodenum, jejunum, and ileum was significantly larger and deeper in green season. Submucosa thickness of duodenum, jejunum, ileum, and rectum was significantly thicker in green season. The muscular thickness of jejunum, cecum, and rectum was significantly thicker in green season.

Conclusion: According to this research, we found that the seasonal changes of ruminal and intestinal morphology of yak showed different length and width papillae, villi, crypt, and submucosa. This fact was confirmed the functional advantages resulting from the ability to successfully adapt to a dry climate and diets, flat, open, and cold grassland may allow yak to overcome both water shortage and energy deficiency in winter.
\end{abstract}

Keywords: green grass, intestine, morphology, Qinghai yak, rumen.

\section{Introduction}

A unique species resource has been formed in Qinghai-Tibetan Plateau, China, under unique climatic conditions and geographical environment. In the Qinghai-Tibetan Plateau animals, face cold weather, low oxygen, short grass period, high radiation, and harsh condition. Plateau species showed strong resistance characteristics. The yak (Bos grunniens), as a year-round grazing animal, is one of the unique livestock in the world. Yak physiology is well adapted to high altitudes, having larger lungs and heart than cattle found at lower altitudes, as well as greater capacity for transporting oxygen through their blood [1] due to the persistence of hemoglobin throughout life [2]. Conversely, yaks do not thrive at lower altitudes [3] and begin to suffer from heat exhaustion above about $15^{\circ} \mathrm{C}\left(59^{\circ} \mathrm{F}\right)$. Further, adaptations to the cold include

Copyright: Ding, et al. Open Access. This article is distributed under the terms of the Creative Commons Attribution 4.0 International License (http://creativecommons.org/licenses/by/4.0/), which permits unrestricted use, distribution, and reproduction in any medium, provided you give appropriate credit to the original author(s) and the source, provide a link to the Creative Commons license, and indicate if changes were made. The Creative Commons Public Domain Dedication waiver (http://creativecommons.org/ publicdomain/zero/1.0/) applies to the data made available in this article, unless otherwise stated. a thick layer of subcutaneous fat and an almost complete lack of functional sweat glands [1].

Gastrointestinal tissues are critical components of the post-absorptive system as they mediate absorption of nutrients and play a role in the regulation of metabolite availability to all other tissues in the body. The ruminal and intestinal tissue can be different and therefore affect the inflow of absorbed nutrients into intermediary organs. In intensively reared cattle receiving higher amounts of concentrates not only the absorption surface of rumen papillae but also the height of duodenal and jejunal villi were seen to increase. This fact was confirmed by the positive correlation between the morphometric parameters of ruminal and intestinal mucosa [4]. In cattle, it has been demonstrated that the starch level in diet did not significantly affect small intestine morphology, but it affected rumen morphology [5]

Moreover, differences in villi and crypts morphology among several breeds cattle were reported [6]. The yaks were grazed on the natural grassland. The various rangelands of the plateau are characterized by their high altitude, short growing season (from June to September), and great seasonal variation in feed supply $[7,8]$.

Although many studies showed that the physiology of the yaks corresponded with that of other 
domestic animals, whereas its body shape was different [8-11], less is known about various seasonal modulation patterns in morphological differences in digestive tract of yak between dry season and green season.

Thus, the objective of this study was to investigate the morphology change of the yak rumen and intestine during the dry season and green season in the Qinghai-Tibetan Plateau.

\section{Materials and Methods \\ Ethical approval}

The samples were removed for routine research scopes, following a procedure approved by the Ethics Committee of the University of Qinghai

\section{Animals and sample collection}

Yaks were grazed on grassland in Henan county, Huangnan Tibetan Autonomous Prefecture, Qinghai Province, China. There are two seasons in terms of the situation of grassland. During summer (from June to September, average temperature $9.6^{\circ} \mathrm{C}$ ), the animals of the reared group grazed on a summer pasture (with plenty of green grass and water), but from later autumn to next early spring (in particular, from the end of October to the middle of May, average temperature $-1.8^{\circ} \mathrm{C}$ ), they were grazed in a winter pasture (with dry hay and snow). Most of plants in Qinghai pasture are Kobresia myosuroides and Elymus nutans. Supplement diet at night was composed of wheat bran $50 \%$, rapeseed dregs $10 \%$, and hay $40 \%$. Four male yaks with the same age (4 years old, good health status) from each season $(4 \times 2=8)$ were randomly selected and slaughtered to determine the effect of different season on intestinal morphology of yak in the Qinghai-Tibetan Plateau. Farmer uses female animals for production so we used male animals only in the study. Samples were taken on the first of March and the first of December.

\section{Histological analysis of the intestinal morphology}

Rumen and segments of approximately $5 \mathrm{~cm}$ of duodenum, jejunum, ileum, cecum, and rectum were obtained before the removal of the entire rumen and intestinal tract. Samples were fixed in $4 \%$ buffered formalin solution for $24 \mathrm{~h}$ and processed for routine paraffin embedding. Serial $4 \mu \mathrm{m}$ transverse sections were cut and stained with hematoxylin and eosin for morphological evaluation. Sections were examined using a light microscope (Leitz, Diaplan) connected to a PC through a Nikon digital system (Digital Sight DS-U1). Images were acquired using the NIS-Elements F version 2.10 software (Nikon) per transverse section of rumen and small intestine. Measurements were made using Image J 1.37V software (National Institutes of Health). 10 well-oriented and intact crypt-villus units of each slide were measured in triplicate. The villi height was defined as the distance from villus tip to crypt junction. The crypt depth was defined as the depth of the invagination between adjacent villi. The muscle thickness was measured from the junction between the submucosal and muscular layers to that between the muscular layer and the tunica serosa. The thickness of intestinal wall was defined as the distance from intestinal external subserosa to the muscular junction layer and submucosa.

\section{Statistical analysis}

Mean values generated from all individual data were statistically analyzed by a one-factor variance analysis using the GLM procedure of the SAS Institute (Cary, NC, USA). Results are expressed as the mean \pm standard error. If the main effect between any group was found to be significant, they were then compared using the Tukey's multiple range test at $\mathrm{p}<0.05$.

\section{Results}

The number, length, and width of papillae and muscular thickness of rumen of yak in different grazing seasons

The number, length, and width of rumen papillae during dry season and green season are summarized in Table-1. Although the number of rumen papillae and muscular thickness of rumen did not significantly change between dry season and green season ( $p>0.05)$, the length and width of rumen papillae significantly increase in green season compared to that in dry season $(\mathrm{p}<0.05)$.

\section{The height of villi of the yak intestine in different grazing seasons}

The height and width of villi during dry season and green season are summarized in Table-2. The height of villi in duodenum and jejunum was significantly higher in green season than that in dry season $(p<0.05)$; however, the height of villi in ileum, cecum, and rectum was not different $(\mathrm{p}>0.05)$. The width of villi on duodenum, jejunum, ileum, and rectum was significantly greater in green season than it in dry season $(\mathrm{p}<0.05)$, on the contrary, in the cecum was lower in green season than in dry season $(\mathrm{p}<0.05)$.

The surface area of villi and crypt depth in the intestine of yak in different grazing seasons

The surface area of villi and crypt depth is summarized in Table-3. The surface area of villi in

Table-1: The number, length, and width of papillae and muscular thickness of rumen of yak in different grazing seasons.

\begin{tabular}{lccc}
\hline Parameters & Dry season & Green season & p-value \\
\hline The number of papillae $\left(\mathrm{n} / \mathrm{cm}^{2}\right)$ & $82.59 \pm 2.75^{\mathrm{A}}$ & $78.37 \pm 1.22^{\mathrm{A}}$ & 0.168 \\
Length $(\mathrm{mm})$ & $5.54 \pm 0.21^{\mathrm{B}}$ & $11.82 \pm 0.36^{\mathrm{A}}$ & 0.002 \\
Width $(\mathrm{mm})$ & $1.32 \pm 0.02^{\mathrm{B}}$ & $2.78 \pm 0.08^{\mathrm{A}}$ & 0.034 \\
Muscular thickness & $379.91 \pm 14.91^{\mathrm{A}}$ & $386.72 \pm 16.68^{\mathrm{A}}$ & 0.284 \\
\hline
\end{tabular}

Means within rows with different superscript capital letters at same day are different $(p<0.05)$ 
duodenum, jejunum, and ileum was significantly larger in green season than that in dry season $(p<0.05)$; on the contrary, surface area of villi in cecum was significantly smaller in green season than that in dry season $(p<0.05)$. However, no significant difference was observed in the rectum. The crypt depth in the duodenum, jejunum, and ileum was greater in green season than that in dry season $(\mathrm{p}<0.05)$, while there was no significant difference in cecum and rectum $(\mathrm{p}>0.05)$.

\section{The submucosa and muscular thickness of the yak intestine in different grazing seasons}

The submucosa and muscular thickness of intestine are summarized in Table-4. Submucosa thickness of duodenum, jejunum, ileum, and rectum was significantly higher in green season than that in dry season $(p<0.05)$; on the contrary, the submucosa thickness of cecum was smaller in green season than that in dry season $(p<0.05)$. The muscular thickness of jejunum, cecum, and rectum was greater in green season than that in dry season $(p<0.05)$, while there was no significant difference between the muscular thickness in duodenum and ileum ( $p>0.05)$.

\section{Discussion}

The extent of morphophysiological variations in the digestive system of ruminants indicates a degree of adaptability for a particular feed [12]. The structure of the mucosal papillae in rumen was closely related with the animal feeding. When the nutritional quality of food is high, a large number of nutrients are degraded into short-chain fatty acids by microorganisms in rumen. Thus, the more plicae and mesh membranes can be formed, the more the surface area of papillae increases so that not only the surface area of original mucosa but also the absorption area in rumen increase $[12,13]$. These findings are in line with the results of the present study which showed that the values of the length and width of the rumen papillae were higher in the green season. Thus the surface and the absorption area were increased. On the contrary, during the dry season characterized by dry grass and lower temperature, the absorption surface decreased by shorter and narrower papillae. This seasonal pattern of the papillae morphology in the yak probably resulted from adaptations to extreme food and environmental conditions. This is consistent with Wang et al. [5] who reported that in the intensively reared group the length and width of rumen papillae were significantly increased when compared to the extensive group of cattle.

Changes in the development of enterocytes and the structure of villi and crypt are direct representation of intestinal environment and may be used as indicators of intestinal health [5]. Zitnan et al. [6] reported

Table-2: The height of villi $(\mu \mathrm{m})$ in the intestine of yak in different grazing seasons.

\begin{tabular}{|c|c|c|c|c|c|c|}
\hline \multirow[t]{2}{*}{ Sections } & \multicolumn{2}{|c|}{ Height of villi } & \multirow[t]{2}{*}{ p-value } & \multicolumn{2}{|c|}{ Width of villi } & \multirow[t]{2}{*}{ p-value } \\
\hline & Dry season & Green season & & Dry season & Green season & \\
\hline Duodenum & $518.47 \pm 23.39^{\mathrm{B}}$ & $791.17 \pm 38.28^{A}$ & 0.012 & $49.64 \pm 1.83^{B}$ & $79.295 \pm 2.67^{A}$ & 0.009 \\
\hline Jejunum & $1246.20 \pm 52.53^{B}$ & $1482.78 \pm 71.70^{A}$ & 0.043 & $142.78 \pm 6.54^{\mathrm{B}}$ & $273.291 \pm 12.03^{A}$ & 0.028 \\
\hline Ileum & $702.77 \pm 35.30^{A}$ & $696.38 \pm 22.54^{A}$ & 0.368 & $98.24 \pm 4.36^{\mathrm{B}}$ & $145.709 \pm 6.25^{A}$ & 0.011 \\
\hline Cecum & $718.18 \pm 33.25^{A}$ & $729.45 \pm 42.68^{\mathrm{A}}$ & 0.714 & $101.51 \pm 4.16^{\mathrm{A}}$ & $76.36 \pm 2.78^{\mathrm{B}}$ & 0.046 \\
\hline Rectum & $578.05 \pm 26.89^{A}$ & $523.24 \pm 36.28^{A}$ & 0.502 & $63.56 \pm 1.95^{\mathrm{B}}$ & $283.684 \pm 10.41^{A}$ & 0.033 \\
\hline
\end{tabular}

Means within rows with different superscript capital letters at same day are different $(p<0.05)$

Table-3: The surface area $\left(\mu \mathrm{m}^{2}\right)$ of villi and crypt depth $(\mu \mathrm{m})$ in the intestine of yak in different grazing seasons.

\begin{tabular}{|c|c|c|c|c|c|c|}
\hline \multirow[t]{2}{*}{ Sections } & \multicolumn{2}{|c|}{ Surface area of villi } & \multirow[t]{2}{*}{ p-value } & \multicolumn{2}{|c|}{ Crept depth } & \multirow[t]{2}{*}{ p-value } \\
\hline & Dry season & Green season & & Dry season & Green season & \\
\hline Duoc & $28667.50 \pm 1497.43^{B}$ & $63970.821 \pm 3070.23^{A}$ & 0.005 & $60.94 \pm 3.36^{B}$ & $69.69 \pm 3.34^{A}$ & 0.361 \\
\hline Jejunum & $175725.26 \pm 13610.75^{B}$ & $423924.33 \pm 21196.72^{A}$ & 0.016 & $45.42 \pm 2.67^{B}$ & $54.33 \pm 2.18^{A}$ & 0.012 \\
\hline Ileum & $67296.19 \pm 3537.39^{B}$ & $99528.92 \pm 4812.31^{\mathrm{A}}$ & 0.009 & $72.16 \pm 3.49^{B}$ & $85.86 \pm 3.57^{A}$ & 0.037 \\
\hline Cecum & $72518.76 \pm 3115.58^{A}$ & $62789.833 \pm 3059.86^{\mathrm{B}}$ & 0.006 & $69.28 \pm 3.01^{\mathrm{A}}$ & $70.28 \pm 3.69^{A}$ & 0.907 \\
\hline Rectum & $23586.24 \pm 1791.27^{A}$ & $222909.27 \pm 10631.81^{A}$ & 0.717 & $78.92 \pm 2.42^{\mathrm{A}}$ & $76.056 \pm 3.26^{\mathrm{A}}$ & 0.829 \\
\hline
\end{tabular}

Means within rows with different superscript capital letters at same day are different $(p<0.05)$

Table-4: The submucosa and muscular thickness $(\mu \mathrm{m})$ of intestine of yak in different grazing seasons.

\begin{tabular}{|c|c|c|c|c|c|c|}
\hline \multirow[t]{2}{*}{ Sections } & \multicolumn{3}{|c|}{ Submucosa thickness } & \multicolumn{3}{|c|}{ Muscular thickness } \\
\hline & Dry season & Green season & p-value & Dry season & Green season & p-value \\
\hline Duodenum & $54.35 \pm 2.79^{B}$ & $124.34 \pm 5.32^{\mathrm{A}}$ & 0.037 & $425.154 \pm 20.67^{A}$ & $413.610 \pm 16.32^{A}$ & 0.589 \\
\hline Jejunum & $79.87 \pm 3.88^{B}$ & $110.335 \pm 4.15^{A}$ & 0.025 & $140.078 \pm 7.95^{в}$ & $239.461 \pm 9.78^{A}$ & 0.024 \\
\hline Ileum & $78.68 \pm 3.54^{B}$ & $109.815 \pm 4.36^{A}$ & 0.001 & $223.821 \pm 9.86^{A}$ & $218.880 \pm 10.59^{A}$ & 0.645 \\
\hline Cecum & $186.49 \pm 9.65^{A}$ & $143.804 \pm 6.94^{B}$ & 0.009 & $269.436 \pm 12.52^{B}$ & $377.496 \pm 18.21^{\mathrm{A}}$ & 0.004 \\
\hline Rectum & $92.54 \pm 4.75^{\mathrm{B}}$ & $153.878 \pm 7.37^{A}$ & 0.014 & $229.460 \pm 9.66^{B}$ & $324.705 \pm 12.94^{A}$ & 0.018 \\
\hline
\end{tabular}

Means within rows with different superscript capital letters at same day are different $(p<0.05)$ 
that the length of duodenal villi in the intensive group was significantly increased compared to the extensive group. Wang et al. [5] revealed that the height of villi increased in duodenum and jejunum of animals fed with concentrate diets. These coincide with our results about the height of villi in the duodenum and jejunum during the green season.

Furthermore, in the green season, we found that the crypt depth in the duodenum, jejunum, and ileum increased; these results were in agreement with that reported in the cattle intestine when fed with higher nutrients feedstuff [6].

Kreikemeier et al. [14] presumed the absorptive surface to represent the mucosal aspect of villi available for nutrient translocation, and the greatest absorptive surface is in the proximal area of the bovine small intestine and increases with increasing grain intake. These coincide with Zitnan et al. [6] and Wang et al. [5] finding results which revealed higher duodenal and jejunal villi surface area in animals fed increased nutrient concentrate diets. In the present experiment, same results are found that the villi surface area on duodenum, jejunum, and ileum increased in green season. These were not consistent with Liu et al. [15] reported that seasonal modulations are more distinct in the jejunum than in the duodenum and the ileum of the small intestines.

Although a little reference was reported that the submucosa thickness and muscular thickness of intestine changes due to diet, in this study, we found that the submucosa thickness and muscular thickness of intestine were increased with increased nutrient concentrate, it contributed to increase the absorption of nutrients in small intestine.

\section{Conclusion}

In this research, we found that the seasonal changes result in the ruminal and intestinal morphology of yak, in particular, the length and width of papillae, villi, crypt, and submucosa. This fact was confirmed the functional advantages resulting from the ability to successfully adapt to a dry climate and diets, flat, open, and cold grassland may allow yak to overcome both water shortage and energy deficiency in winter.

\section{Authors' Contributions}

This work was carried out in collaboration between all authors. BAD, SQM, and ZRL: Designed the experimental procedures. BAD and SQM: Conducted the research work. XLL and SRM: Helped in data analysis and revision. All authors read and approved the final manuscript.

\section{Acknowledgments}

This study was supported by grants from the Ministry of Science and Technology of the People's Republic of China (Grant No. 2015DFG31870) and the Science and Technology Department of Qinghai Province (Grant No. 2015-HZ-801).

\section{Competing Interests}

The authors declare that they have no competing interests.

\section{References}

1. Gerald, W., Han, J.L. and Long, R.J. (2003) The Yak in Relation to Its Environment. In: The Yak. $2^{\text {nd }}$ ed. Regional Office for Asia and the Pacific Food an Agriculture Organization of the United Nations, Bangkok.

2. Sarkar, M., Das, D.N. and Mondal, D.B. (1999) Fetal haemoglobin in pregnant yaks (Poephagus grunniens L.). Vet. J., 158(1): 68-70.

3. Mason, I.L. (1984) 12 Yak, Animal genetics training resources version II: Breed Information. In: Evolution of Domesticated Animals. Longman, London. p39-45.

4. Zitnan, R., Kuhla, S., Nurnberg, K., Schoenhusen, U., Ceresnakova, Z., Sommer, A., Baran, M., Greserova, G. and Voigt, J. (2003) Influence of the diet on the morphology of ruminal and intestinal mucosa and on intestinal carbohydrase levels in cattle. Vet. Med., 48: 177-182.

5. Wang, Y.H., Xu, M., Wang, F.N., Yu, Z.P., Yao, J.H., Zan, L.S. and Yang, F.X. (2009) Effect of dietary starch on rumen and small intestine morphology and digesta $\mathrm{pH}$ in goats. Livest. Sci., 122(1): 48-52.

6. Zitnan, R., Voigt, J., Kuhla, S., Wegner, J., Chudy, A., Schoenhusen, U., Brna, M., Zupcanova, M. and Hagemeister, H. (2008) Morphology of small intestinal mucosa and intestinal weight change with metabolic type of cattle. Vet. Med., 53(10): 525-532.

7. Long, R.J., Dong, S.K., Wei, X.H. and Pu, X.P. (2005) The effect of supplementary feeds on the bodyweight of yaks in cold season. Livest. Prod. Sci., 93(3): 197-204.

8. Ozgel, O., Duzler, A., Dursun, N. and Beyaz, F. (2009) The morphology of the cervico thoracic sympathetic system in donkeys (Equus asinus L.), Anat. Histol. Embryol., 38: 139-144.

9. Kabak, M. (2007) The gross anatomy of the cranial cervical ganglion in the guinea pig (Cavia porcellus). Vet. Res. Commun., 31(1): 17.

10. Shao, B.P., Ding, Y.P., Xie, Z.H., Yu, H.X., Brand-Saberi, B. and Wang, J.L. (2007) The cranial cervical ganglion and its branches in the yak (Bos grunniens). Vet. J., 173(1): 174-177.

11. Wang, J.B., Zhang, R., Zhang, L., Wang, C.J., Shao, B.P. and Wang, J.L. (2015) Histomorphometric adaptation of yak (Bos grunniens) abomasum to the Qinghai-Tibetan plateau environment. Int. J. Morphol., 33(2): 764-776.

12. Bannink, A., France, J., López, S., Gerrits, W.J.J., Kebreab, E., Tamminga, S. and Dijkstra, J. (2008) Modelling the implications of feeding strategy on rumen fermentation and functioning of the rumen wall. Anim. Feed Sci. Technol., 143: 3-26.

13. Wang, J.B., Li, H.Y., Zhang, L., Zhang, Y., Yue, M.X., Shao, B.P. and Wang, J.L. (2014) Histomorphometric characterization of forestomach of Yak (Bos grunniens) in the Qinghai-Tibetan plateau. Int. J. Morphol., 32(3): 871-881.

14. Kreikemeier, K.K., Harmon, D.L., Peters, J.P., Gross, K.L., Armendark, C.K. and Krehbiel, C.R. (1990) Influence of dietary forage and feed intake on carbohydrase activities and small intestinal morphology of calves. J. Anim. Sci., 68: 2916-2929.

15. Liu, Q.S., Zhang, Z.Q., Enrique, C.V. and Wang, D.H. (2013) Seasonal plasticity of gut morphology and small intestinal enzymes in free-living Mongolian gerbils. $J$. Comp. Physiol. B, 183: 511-523. 